\title{
Reducing Emissions from Deforestation and Forest Degradation: Opportunities and Pitfalls in Developing a New Legal Regime
}

\author{
lan Fry
}

Deforestation of tropical forests contributes approximately $10-20 \%$ of global greenhouse gas emissions. This paper reviews various options proposed by countries to address reducing these emissions, including marketbased approaches to fund activities to make these reductions. The paper explores some of the opportunities and pitfalls of market-based mechanisms, including such concepts as permanence, measurement, additionality, undermining the carbon market and sovereignty concerns. Possibly the greatest difficulty with market-based approaches is the issue of emissions displacement - a concept often called 'leakage'. One cause of leakage is the growing market for tropical timber, particularly in China. Options to address leakage are considered, including a new concept relating to carbon deficits as part of a demand-side management approach. Non-market mechanisms are also explored. Elements of the United Nations Framework Convention on Climate Change (UNFCCC)'s Bali Action Plan, such as conservation, sustainable management of forests and the enhancement of carbon stocks, are also examined. The paper concludes that a step-by-step approach is needed to build the capacity of developing countries to meet the challenges of reducing emissions from deforestation in developing countries (REDD).

At the United Nations Framework Convention on Climate Change (UNFCCC) Conference of Parties (COP)'s thirteenth session in Bali, parties adopted a decision on reducing emissions from deforestation in developing countries (REDD). ${ }^{1}$ This decision was linked to another broader decision entitled the 'Bali Action Plan', which makes reference to work on reducing emissions from deforestation and forest degradation in developing countries. ${ }^{2}$ Also of note is an element of the Bali Action Plan that provides a rather

\footnotetext{
${ }^{1}$ Decision 2/CP.13, Reducing Emissions from Deforestation in Developing Countries: Approaches to Stimulate Action in Report of the Conference of the Parties on its Thirteenth Session, held in Bali from 3 to 15 December 2007 (FCCC/CP/2007/6/Add.1, 14 March 2008). See also UNFCCC (New York, 9 May 1992).

${ }^{2}$ The relevant text in the Bali Action Plan states: '1. Decides to launch a comprehensive process to enable the full, effective and

oblique opportunity for REDD issues to be considered in the context of enhancing action on adaptation. ${ }^{3}$ By virtue of these decisions, the COP has established a process to develop a new legal instrument to address, inter alia, these issues. Whether this becomes a stand-alone agreement on REDD or is encompassed by a broader agreement on long-term cooperative action to address climate change remains to be seen. Either way, a new legal agreement on REDD provides various opportunities and pitfalls. This paper explores some of these and suggests a way forward.

Consideration of deforestation in the context of the UNFCCC and the Kyoto Protocol goes back some years. Some parties wanted the concept of 'avoided deforestation' included as an eligible activity under the Clean Development Mechanism (CDM) of the Kyoto Protocol, in the first commitment period. ${ }^{4}$ This proposal was rejected due to a number of methodological concerns including additionality, permanence, baseline setting and leakage (see the discussion below of these terms) ${ }^{5}$ and reservations about these methodological issues still remain for some parties to the UNFCCC. ${ }^{6}$ As a result, 'avoided deforestation'

sustained implementation of the Convention through long-term cooperative action, now, up to and beyond 2012, in order to reach an agreed outcome and adopt a decision at its fifteenth session, by addressing, inter alia: 1(b)(iii) Policy approaches and positive incentives on issues relating to reducing emissions from deforestation and forest degradation in developing countries; and the role of conservation, sustainable management of forests and enhancement of forest carbon stocks in developing countries' (Decision 1/CP.13, Bali Action Plan, in Report of the COP, ibid).

${ }^{3}$ See para. 1(c) of the Bali Action Plan, ibid.

${ }^{4}$ See the discussion of this issue in I. Fry, 'Twists and Turns in the Jungle: Exploring the Evolution of the Land Use, Land-Use Change and Forestry Decisions Within the Kyoto Protocol', 11:2 RECIEL (2002), 167.

${ }^{5}$ See G-J. Nabuurs et al., 'Forestry', in B. Metz et al. (eds), Climate Change 2007: Mitigation: Contribution of Working Group III to the Fourth Assessment Report of the Intergovernmental Panel on Climate Change (Cambridge University Press, 2007), 566.

${ }^{6}$ See submission made by Belize, Bolivia, Central African Republic, Congo, Costa Rica, Democratic Republic of Congo, Dominican Republic, Equatorial Guinea, Gabon, Ghana, Guatemala, Honduras, Kenya, Lesotho, Liberia, Madagascar, Panama, Papua New Guinea, Sierra Leone, Solomon Islands, Thailand, Uganda, Vanuatu and Viet Nam, 
was not included in the CDM in the first commitment period of the Kyoto Protocol. The only forest-related activities available for developing countries under the CDM are afforestation and reforestation. It was considered that these activities were easier to measure and that issues arising from them, such as leakage, were not difficult to assess.

The idea of a new agreement on REDD was first introduced to parties at the Seminar of Government Experts in Bonn, May 2005, by the Ambassador to Papua New Guinea, Robert Aisi. This was followed up by a submission by Papua New Guinea and Costa Rica, which suggested two possible pathways for reducing emissions from deforestation. The first was to develop a protocol on 'RED'8 and the second was to revise the Marrakesh Accords and to allow 'avoided deforestation' as a project activity under the CDM in the first commitment period. ${ }^{9}$

Concern about emissions from deforestation and forest degradation is well founded and was noted in the Stern Review, which examined the economics of climate change. Stern found that the loss of natural forests around the world contributes more to global emissions each year than does the transport sector. In fact, estimates suggest that the relative contribution of greenhouse gas emissions from deforestation and forest degradation range between $10-25 \%$ of global emissions. ${ }^{10}$ The extent to which these emissions are derived from deforestation activities (the conversion of forest land to non-forest land) or degradation (the decrease of carbon stocks per unit area not resulting from the reduction or disappearance of forest cover $)^{11}$

Views on Issues Related to Further Steps under the Convention Related to Reducing Emissions from Deforestation in Developing Countries: Approaches to Stimulate Action, 2007 (UNFCC/SBSTA/ 2007/MISC.14, 10 September 2007), at 7.

${ }^{7}$ See K. Kulovesi, M. Muñoz and C. Spence, 'Summary of the UNFCCC Seminar of Governmental Experts, 16-17 May 2005', 12:261 Earth Negotiations Bulletin (19 May 2005), 4.

${ }^{8}$ At this stage forest degradation, the second ' $D$ ', had not entered into the discussion.

${ }^{9}$ See submission by the Governments of Papua New Guinea and Costa Rica, Reducing Emissions from Deforestation in Developing Countries: Approaches to Stimulate Action (FCCC/CP/2005/MISC.1, 11 November 2005).

${ }^{10}$ The Stern Review suggests $18 \%$. See N. Stern, Stern Review on the Economics of Climate Change: Executive Summary (Cambridge University Press, 2007), at iv, available at: <http://www.hmtreasury.gov.uk/media/9/9/CLOSED_SHORT_executive_summary.pdf>. Some parties quote from the Intergovernmental Panel on Climate Change (IPCC) and suggest a range of $10-25 \%$. See Governments of Bolivia, Costa Rica, Nicaragua and Papua New Guinea, 'Reducing Emissions from Deforestation in Developing Countries: Approaches to Stimulate Action', in Issues Relating to Reducing Emissions from Deforestation in Developing Countries and Recommendations on any Further Process (FCCC/SBSTA/2006/MISC.5, 11 April 2006), (Issues), at 26.

${ }^{11}$ A definition was suggested by a number of Congo Basin countries. See Democratic Republic of the Congo, Cameroon, Central African Republic, Republic of Congo, Equatorial Guinea and is difficult to assess. ${ }^{12}$ Due to the difficulty of differentiating between the two concepts, Indonesia has proposed a revision of the definition of deforestation (which is found in Decision 16/CMP.1 ${ }^{13}$ to include actions that lower carbon stocks, such as fires. ${ }^{14}$ Both deforestation and forest degradation are significant sources of emissions and subsequently it was generally accepted by parties at COP 13 to be a collective issue that needed to be addressed. ${ }^{15}$

Apart from the notion of reducing emissions from deforestation and forest degradation, three other concepts were introduced into the Bali Action Plan and the COP 13 decision on reducing emissions from deforestation. The other elements are: 'the role of conservation, sustainable management of forests and enhancement of forest carbon stocks in developing countries'. ${ }^{16}$ These three actions are separated from the rest of the sentence in the Decision, which refers to policy approaches and positive incentives on issues relating to reducing emissions from deforestation and forest degradation in developing countries, by a semi-colon, inferring that these actions would not be subject to the same policy approaches and positive incentives developed for REDD. Part of the reason for this separation is due to the difference between reducing emissions from deforestation and 'avoided deforestation' - a term often used for the conservation of existing carbon stocks. In essence, it infers that no country should get carbon credits for doing nothing to their carbon stocks as there is, essentially, no change in the stocks. Brazil was most adamant in ensuring that incentive measures would be different for these two concepts. ${ }^{17}$ This is consistent with the fourth principle found in Decision 16.CMP.1 on land use, land-use change and forestry, i.e. that the mere presence of carbon stocks be excluded from accounting. ${ }^{18}$ The additional three terms will be discussed below.

Gabon, Views on Issues Related to Further Steps under the Convention Related to Reducing Emissions from Deforestation in Developing Countries: Approaches to Stimulate Action, 2007 (UNFCCC/SBSTA/2007/ MISC. 14, 10 September 2007), at 26.

12 See statement to this effect by Tuvalu, Views on the Range of Topics and Other Relevant Information Relating to Reducing Emissions from Deforestation in Developing Countries (FCCC/SBSTA/2007/ MISC.2/Add.1), 3 April 2007.

${ }^{13}$ In Decision 16/CMP.1, Land Use, Land-Use Change and Forestry (FCCC/KP/CMP/2005/8/Add.3, 30 March 2006), Annex, 'deforestation' is the direct human-induced conversion of forested land to nonforested land.

${ }^{14}$ See Indonesia, Views on the Range of Topics and Other Relevant Information Relating to Reducing Emissions from Deforestation in Developing Countries (FCCC/SBSTA/2007/MISC.2/Add.1, 3 April 2007), at 6 .

${ }^{15}$ Personal observation.

${ }^{16}$ See Decision 2/CP.13, n. 1 above, para. 11.

${ }^{17}$ Personal observation.

${ }^{18}$ See Decision 16/CMP.1, n. 13 above, para. 1(d). 


\section{UNDERLYING CAUSES OF DEFORESTATION AND FOREST DEGRADATION}

In consideration of how to reduce emissions from deforestation and forest degradation, parties are faced with a significant challenge. The causes of deforestation and forest degradation are vast and complicated. There are considerable regional differences between the rainforested countries. Geist and Lambin, for example, suggest that deforestation is driven by identifiable regional patterns of causal factors, of which the most prominent are economic factors, institutions, national policies and remote influences driving agricultural expansion, wood extraction and infrastructure extension. ${ }^{19}$ They suggest that the extension of overland transport infrastructure, followed by commercial wood extraction, permanent cultivation and cattle ranching, are the leading proximate causes of deforestation. Contrary to widely held views, they suggest that shifting cultivation is not the primary cause of deforestation. ${ }^{20}$

Others suggest that population densities and changes, market access, soil quality, lack of secure tenure and changes in land use such as large-scale agriculture are the primary causes of deforestation. ${ }^{21}$ For yet others, fires and illegal logging register as significant causes. ${ }^{22}$

While these are fairly broad descriptors, they do suggest that the issues are complex and that durable solutions to address deforestation and forest degradation within the context of the UNFCCC will not be easily found. In fact, other international institutions have struggled with this issue for many years and have been profoundly unsuccessful in addressing deforestation. By its own admission, the International Tropical Timber Organization (ITTO) has witnessed the dramatic decline in forest area since its inception. ${ }^{23}$ Others suggest that

\footnotetext{
${ }^{19}$ H.J. Geist and E.F. Lambin, 'Proximate Causes and Underlying Driving Forces of Tropical Deforestation', 52:2 Bioscience (2002), 143. ${ }^{20}$ Ibid., at 146 .

${ }^{21}$ These are suggested by Ghazal Baiozamani of the United Nations Forum on Forests (UNFF). See K. Alvarenga and W. McPherson, 'A Summary Report of the Wilton Park Conference on Forestry: A Sectoral Response to Climate Change', 130:1 Wilton Park Conference Bulletin (26 November 2006), at 6.

${ }^{22}$ See Indonesia, n. 14 above, at 7.

${ }^{23}$ The ITTO states that in all three ITTO producer regions, forest coverage has been declining since the inception of the ITTO (in 1986): in Africa, from $49.3 \%$ of total land area in 1985 to $44.2 \%$ in 2005 ; in Asia, from $41.4 \%$ in 1985 to $35.4 \%$ in 2005 ; and in Latin America from $59.4 \%$ in 1985 to $52.4 \%$ in 2005 . For all ITTO producer countries as a whole, the decline was from $52.7 \%$ in 1985 to $46.4 \%$ in 2005 . See ITTO, Annual Review and Assessment of the World Timber Situation (Document GI-7/06, 2006), at v.
}

the UN Forum on Forests (UNFF) is also ill-equipped to address this issue. ${ }^{24}$

It would be reasonable to suggest that the niche position of the UNFCCC in the context of REDD is to develop a legal instrument that effectively reduces emissions from deforestation and forest degradation as a contribution to achieving the ultimate objective of the Convention, as defined in its Article $2 .^{25}$ Therefore, any actions to address REDD should provide 'a real benefit for addressing the climate'. ${ }^{26}$ While this may be selfevident, there is the potential to develop actions associated with deforestation and forest degradation that may not necessarily contribute to combating climate change (see discussion below). Local actions may not lead to global climate benefits. While REDD actions may have benefits for biodiversity at the local level, if the actions are not successful in a climate sense, they may also lead to adverse effects on biological diversity on a broader scale. Recent studies suggest that rainforests could become irrevocably damaged due to rising global temperatures as a result of climate change. ${ }^{27}$ Furthermore, if measures to reduce emissions from deforestation fail to have any climate change benefits, other biologically diverse ecosystems, such as coral reefs, will also suffer. ${ }^{28}$ This is a crucial factor in developing a comprehensive legal regime. Climate change must be the primary concern.

The proposal for a new legal regime on reducing emissions from deforestation falls basically within two camps: market-based approaches and non-market-based approaches, although some countries appear to be suggesting both options, while other countries are suggesting a variety of actions which have been called the 'basket approach' (see discussion below).

\footnotetext{
${ }^{24}$ According to Sergio Jauregui of the United Nations Environment Programme (UNEP), the UNFF is not equipped with strong tools for international policy enforcement, its recommendations do not commit parties to take action and it has no mandate for decision making. See his comments in K. Alvarenga and W. McPherson, n. 21 above, at 6 .

${ }^{25}$ Article 2 of the UNFCCC states: 'The ultimate objective of this Convention and any related legal instruments that the Conference of Parties may adopt is to achieve, in accordance with the relevant provisions of the Convention, stabilization of greenhouse gas concentrations in the atmosphere at a level that would prevent dangerous anthropogenic interference with the climate system. Such a level should be achieved within a time-frame sufficient to allow ecosystems to adapt naturally to climate change, to ensure that food production is not threatened and to enable economic development to proceed in a sustainable manner'. See UNFCCC, n. 1 above, Article 2.

${ }^{26}$ As noted by the Democratic Republic of the Congo et al., n. 11 above, at 27 .

${ }^{27}$ This fact is noted in the Stern Review, see N. Stern, n. 10 above, at vii.

${ }^{28}$ O. Hoegh-Guldberg et al., 'Coral Reefs Under Rapid Climate Change and Ocean Acidification', 318:5857 Science (14 December 2007), 1737
} 


\section{MARKET-BASED APPROACHES}

Ostensibly, market-based approaches in this context are focused on the generation of carbon credits that are sold in an international market and the money that is generated from these sales is used to support REDD actions. Within this general notion of the tradeable carbon market there are two clear options:

i. national approaches;

ii. sub-national market approaches.

Each is discussed below.

\section{NATIONAL MARKET APPROACHES}

The nature of the national approach has not been fully described by any party, but elements of the approach can be inferred from party submissions. It involves establishing a national baseline or reference scenario. Historic emissions are calculated and a developing country makes a pledge to reduce emissions below this baseline. Emissions reductions are calculated and these reductions are credited to the developing country and then sold on the international carbon market. Presumably, the developing country party would set its own target. The nature of how this target would be legally inscribed, as part of an agreement, is rather vague, although four countries (Bolivia, Costa Rica, Nicaragua and Papua New Guinea) have jointly proposed that an additional Annex to the Kyoto Protocol could be established for developing countries to make REDD commitments. ${ }^{29}$ Presumably any additional reduction below the business as usual baseline would then be eligible for trading as Assigned Amount Units (AAUs) established under the emissions trading provisions of the Kyoto Protocol..$^{30}$ Another option being suggested by the Intergovernmental Panel on Climate Change (IPCC) is to set 'no-lose' targets, whereby emission allowances could only be sold if a target is reached and any excess reductions below that target could be sold.$^{31}$ If the target was not reached, no penalty would apply, hence the term 'no lose'.

Currently discussions on REDD have been undertaken in the context of the UNFCCC rather than the Kyoto Protocol and within the context of the Ad hoc Working Group on Long-term Cooperative Action (AWG-LCA). A discussion on how a new legal arrangement developed under the AWG-LCA will link with the Kyoto Protocol is still pending. This is due to political sensitivities associated with Annex I target setting for the second commitment period under the Kyoto Protocol, and

\footnotetext{
${ }^{29}$ See Governments of Bolivia et al., n. 10 above, at 31.

30 Ibid.

${ }^{31}$ See G-J. Nabuurs et al,. n. 5 above, at 567.

(C) 2008 The Author. Journal compilation (c) 2008 Blackwell Publishing Ltd.
}

possible target setting for developing countries under a new agreement established by the AWG-LCA. A proposal for an Annex C to the Kyoto Protocol appears to be the first step in making this link.

A larger collection of countries (which includes the four 'Annex C' proposers) has suggested establishing a REDD mechanism, but the nature of this mechanism is not clear. It would appear to involve target setting, establishing national baselines and then selling emissions reductions on an international carbon market under a new legal agreement. ${ }^{32}$ Evidently this larger collection of countries is not so keen to sign up to commitments under the Kyoto Protocol, as their submissions do not mention Kyoto commitments as an option.

An alternative approach being proposed by Mexico is to broaden the CDM to take on a sectoral or programmatic approach. Under this proposal, a country could elect to undertake a reduction of emissions from deforestation and forest degradation for the entire country and credits generated from this activity would be sold as certified emissions reductions under the $\mathrm{CDM}^{33}$ Again we are seeing a link back to the Kyoto Protocol.

\section{SUB-NATIONAL MARKET APPROACHES}

Some countries have suggested that sub-national REDD projects should be eligible under the CDM..$^{34,35}$ Rather than national baselines, project baselines would be established and reductions below that baseline would be converted into certified emissions reductions. Presumably, sub-national REDD projects would operate under similar modalities to project-based activities under the CDM. Colombia was a lead proponent of this idea, presumably because the national government may

\footnotetext{
${ }^{32}$ See Bolivia, Central African Republic, Costa Rica, Democratic Republic of the Congo, Dominican Republic, Fiji, Ghana, Guatemala, Honduras, Kenya, Madagascar, Nicaragua, Panama, Papua New Guinea, Samoa, Solomon Islands, Vanuatu, Views on the Range of Topics and Other Relevant Information Relating to Reducing Emissions from Deforestation in Developing Countries (FCCC/ SBSTA/2007/MISC.2, 2 March 2007), (Views), at 16.

${ }^{33}$ See Mexico, Views on the Range of Topics and Other Relevant Information Relating to Reducing Emissions from Deforestation in Developing Countries, ibid., at 72 . Mexico also suggests that REDD activities could be undertaken as smaller projects under the CDM. ${ }^{34}$ The Annex $\mathrm{C}$ group of countries also proposed a sectoral CDM. How this would play out against an Annex C to the Kyoto Protocol is unclear.

${ }^{35}$ Other collections of countries proposed a sectoral CDM. See, for example, Chile, Views on the Range of Topics and Other Relevant Information Relating to Reducing Emissions from Deforestation in Developing Countries, n. 32 above, at 26; and Costa Rica on behalf of Costa Rica, Dominican Republic, Guatemala, Honduras, Mexico, Panama, Paraguay and Peru, Views on the Range of Topics and Other Relevant Information Relating to Reducing Emissions from Deforestation in Developing Countries, n. 32 above, at 36.
} 
not have sufficient control over its territory to feel confident in developing a national baseline. Colombia further suggests that a sectoral CDM could be developed under the Kyoto Protocol or a similar arrangement could be developed under UNFCCC. ${ }^{36}$

Creating a separate mechanism under the UNFCCC is logical in one sense in that it has the potential to include the USA into a trading system. Legislators in the USA have already signalled an interest in establishing a carbon market and other measures associated with reducing emissions from deforestation and forest degradation through the development of America's Climate Security Act bill. ${ }^{37}$ This bill directs the Administrator of the Environmental Protection Agency to establish a programme to decrease emissions of greenhouse gases through various means, including the establishment of a domestic emissions trading scheme.

\section{NEW MONEY AND NEW OPPORTUNITIES}

Clearly the most significant element of the market approaches, both national and sub-national, is the belief that they will bring in large sums of new money to attack deforestation and forest degradation. The proponents of the market-based approaches suggest that a policy that dedicated $20 \%$ of the trading volume from existing emissions trading markets to address deforestation would likely generate revenues that are sufficient to reduce global emissions from deforestation by $50 \%$ over the coming decades. ${ }^{38}$ It remains to be seen whether this claim can be substantiated. There are many factors that could influence the carbon market if REDD was included. Nevertheless, the need for new money is apparent. According to Stern, the opportunity cost of forest protection in eight countries, responsible for $70 \%$ of emissions from land use, could be around US $\$ 5$ billion per annum initially, although over time Stern believes that the marginal costs would rise. ${ }^{39}$ Some, including the IPCC, have even gone so far as to suggest that at a price of US\$27.2 per tonne of carbon dioxide, deforestation could potentially be

\footnotetext{
${ }^{36}$ See Colombia, Views on the Range of Topics and Other Relevant Information Relating to Reducing Emissions from Deforestation in Developing Countries, n. 32 above, at 29.

${ }^{37}$ See America's Climate Security Act, Section 2191 (18 October 2007). This is generally known as the Lieberman-Warner Climate Security Act. At the time of writing of this paper, the bill was in its first stage of the legislative process. It has been referred to two committees for consideration: the Senate Environment and Public Works and the Senate Environment and Public Works, Subcommittee on Private Sector and Consumer Solutions to Global Warming and Wildlife Protection. The bill has a number of relevant provisions, most notably Section 3805 on International Forest Carbon Activities, which relates to the reduction in deforestation and forest degradation.

${ }^{38}$ See Bolivia et al., n. 32 above, at 12.

${ }^{39}$ See N. Stern, n. 10 above, at xxvi.
}

๑) 2008 The Author. Journal compilation @ 2008 Blackwell Publishing Ltd. virtually eliminated..$^{40}$ Cost predictions of this type are highly questionable as they are based on the somewhat simplistic notion that money will buy out the drivers of deforestation and forest degradation. They also appear to be based on an oversimplified estimate of abatement costs. ${ }^{41,42}$

Additionally, it has been suggested that 'readiness' activities, that is preparatory measures to enter the market, may require US $\$ 1-5$ million per developing country. ${ }^{43}$ These readiness activities would aim to build the capacity of tropical forest countries to undertake national forest inventories and to develop various means to control deforestation and forest degradation.

\section{EARLY CREDITING}

Linked to a number of proposals for market-based approaches in REDD is the notion of early crediting. Initially this started as a proposal to re-open agreements already made for the first commitment period of the Kyoto Protocol. Then, the proponents apparently realised the political cost of opening up old, hard-fought agreements and subsequently opted for early crediting. Fundamentally this means that emissions reductions undertaken prior to the end of the first commitment period could be eligible for use in carbon markets in the second commitment period. In essence, this would equate to the banking of carbon credits. The 'Annex C' group of countries proposed this concept. ${ }^{44,45}$ This is a

\footnotetext{
${ }^{40}$ See the reference to Sohngen and Sedjo, in G-J. Nabuurs et al., n. 5 above, at 552 .

${ }^{41}$ A fact noted by Luiz Gylvan Meira Filho. See K. Alvarenga and W. McPherson, n. 21 above, at 4.

${ }^{42}$ See also comments made by Janet Redman, who questions the World Bank's belief that a cap and trade regime for REDD will motivate investment in transformational technologies. See J. Redman, World Bank: Climate Profiteer (Sustainable Energy and the Economy Network Institute for Policy Studies, April 2008), at 11, available at: <www.ips-dc.org/getfile.php?id>.

${ }^{43}$ See Belize et al., n. 6 above, at 6.

${ }^{44}$ See Bolivia et al., n. 32 above, at 29. Costa Rica suggest that non-Annex I parties that voluntarily elect or have early elected as a national policy to reduce their emissions from deforestation, on a project by project basis, during the six years previous to the end of the first commitment period of the Kyoto Protocol, would be financially compensated by Annex I parties on the basis of their performance, taking into account an average representative annual deforestation rate over some agreed period in the past, measured with satellite imagery techniques, as a baseline. See Republic of Costa Rica, Reducing Emissions from Deforestation in Developing Countries: Approaches to Stimulate Action (FCCC/SBSTA/2006/ MISC.5, 11 April 2006), at 63.

${ }^{45}$ Portugal on behalf of the European Community also suggested in its submission that pilot activities pre-2013 could be 'integrated' into a post-2012 agreement - which one could argue is an oblique reference to early crediting. See Portugal on behalf of the European Community and its Member States, Views on Issues Related to Further Steps under the Convention Related to Reducing Emissions from Deforestation in Developing Countries: Approaches to Stimulate Action, 2007, UNFCC/SBSTA/2007/MISC.14, 10 September 2007, at 47 .
} 
highly controversial proposal as it provides for new sources of carbon to enter the market without knowing what emissions reductions targets will be set for Annex I parties in the second commitment period of the Kyoto Protocol, or what commitments will be made within a new agreement under the Convention. Discussions concerning 'early action' were particularly tense at COP 13 in Bali, as the implications for target-setting touched on a number of political sensitivities. ${ }^{46}$ In the end, reference to 'early action' did not appear in the REDD decision text. ${ }^{47}$

Another approach being considered in the context of 'early action' is to apply the provisions of Article 4.2(a) of the Convention. This allows for Annex I parties to implement policies and measures jointly with other parties. Germany, on behalf of the European Community, suggested that 'activities implemented jointly' (AIJ) could be used in a pilot phase of a REDD mechanism, in a similar fashion to how pilot AIJ projects were developed prior to the establishment of the CDM and Joint Implementation under the Kyoto Protocol. ${ }^{48}$ While on the surface this appears to be a reasonable approach, it could create expectations that pilot projects would be eligible for funding under a future REDD mechanism. Similar problems, where expectations were created and not fulfilled, were experienced with pre-CDM AIJ projects. This created a certain level of acrimony and distrust during negotiations of the rules for the CDM. ${ }^{49}$

Nevertheless, there is an urgent need to address deforestation and forest degradation in developing countries. As such, there are actions that could be established ahead of any fully functional REDD mechanism. These could include, inter alia: capacitybuilding programmes for assessing deforestation rates, assessment schemes of national implementation policies to combat deforestation and processes to define baselines or reference scenarios. ${ }^{50}$ These have been considered by many as 'readiness' activities.

\section{THE PITFALLS OF MARKET- BASED APPROACHES}

While the thought of new money to address deforestation and forest degradation is very alluring, there are a number of pitfalls associated with carbon markets and

\footnotetext{
${ }^{46}$ See P. Doran et al., 'COP 13 and COP/MOP3 Highlights', 12:352 Earth Negotiations Bulletin (13 December 2007).

${ }^{47}$ See Decision 2/CP.13, n. 2 above.

${ }^{48}$ See Germany on behalf of the European Community and its Member States, Views, n. 32 above, at 54.

${ }^{49}$ Personal observation.

${ }^{50}$ Some of these actions were suggested by Germany on behalf of the European Community, see n. 48 above, at 53.
}

more generally with realising action to reduce emissions. These pitfalls can be characterized under the following themes: measurement, permanence, undermining the market, leakage, and additionality, and sovereignty and rights to land.

\section{MEASUREMENT}

Measuring changes in carbon stocks in complex forest ecosystems poses a number of challenges. Establishing baselines for national market approaches requires a comparison of deforestation rates over different time periods. In recent years, there have been significant improvements in forest assessment processes using satellite imagery and multi-spectral aerial digital imagery. ${ }^{51}$ Nevertheless, satellite imagery has its limitations. ${ }^{52}$ Assessments of forest degradation are more complicated ${ }^{53}$ and tend to require groundwork, although techniques are being developed using light detection and ranging technologies (LIDAR). ${ }^{54}$ However, these systems are expensive to use and may not be a financially viable option for many developing countries. Whatever approach is considered, it should be transparent and consistent across all countries.

Inevitably, remote sensing and ground-based data will be needed and, as suggested by Germany on behalf of the European Community, there will always be a requirement for an appropriate monitoring system..$^{55}$ In this context, IPCC guidance for greenhouse gas estimation could provide the basis for a recognized system of monitoring, ${ }^{56}$ although the current 2006 IPCC Guidelines for Greenhouse Gas (GHG) Inventories suggest a 60\% uncertainty on the reports on changes in carbon stocks. ${ }^{57}$ According to the International Centre for Research in Agroforestry (ICRAF), this is the single biggest

\footnotetext{
${ }^{51}$ See S.J. Scherr et al., Developing Future Ecosystem Service Payments in China: Lessons Learned from International Experience (Forest Trends, 2006), at 43, available at: <www.forest-trends.org/ documents/publications/CCICED\%20Taskforce\%20Report\%20v105\% 20Aug\%208\%202006.pdf $>$.

${ }^{52}$ Experience in Vanuatu suggests that satellite imagery is limited in areas of cloud cover and assessments of canopies where invasive species create confusion with species identification. See Vanuata, in Views, n. 32 above, at 89. Furthermore, assessing carbon stocks of the many different species found in rainforests presents many challenges and, according to the Global Terrestrial Observing System, estimates of carbon stocks of forests undergoing deforestation are less well known. See Global Terrestrial Observing System, in Views, n. 32 above, at 23. See also similar views expressed by Norway, 'Reducing Emissions from Deforestation in Developing Countries: Approaches to Stimulate Action', in Issues, n. 10 above, at 100.

${ }^{53}$ As noted by Japan. See FCCC/SBSTA/2007/MISC.2, 2 March 2007 , at 63 .

${ }^{54}$ See, Thailand, in Views, n. 32 above, at 82.

${ }^{55}$ See Germany on behalf of the European Community, n. 48 above, at 54 .

${ }^{56}$ A point noted by Bolivia et al., n. 32 above, at 12 .

${ }^{57} \mathrm{~S}$. Eggleston et al. (ed), 2006 IPCC Guidelines for National Greenhouse Gas Inventories (Institute for Global Environmental Strategies, 2006).
} 
uncertainty in GHG quantification. ${ }^{58}$ Furthermore, there are complications with the IPCC's use of the term 'unmanaged forest' as a proxy for non-anthropogenic emissions in forested lands..$^{59}$ Inevitably the IPCC will need to develop further methodologies ${ }^{60}$ and consider changes to its definitional approaches.

In considering the development of an international REDD mechanism that will provide broad coverage, a capacity building and technology transfer scheme will need to be developed to ensure that all rainforested developing countries have the necessary expertise and access to the necessary assessment and monitoring technology. ${ }^{61}$ This may simply not be possible in the near future. But the ability to have inventory and monitoring systems for all rainforested countries may need to be a prerequisite before a national market system is introduced. Otherwise, as Norway suggests, the overall effectiveness of an international market-based instrument may be placed in question. ${ }^{62}$

\section{PERMANENCE}

Any system that establishes a market approach to offset emissions needs to ensure that the offsets are permanent, otherwise there is no gain for addressing climate change. In the case of reducing emissions from deforestation and forest degradation, guaranteeing that reductions in emissions will be permanent is extremely difficult. Recent studies of deforestation rates in Brazil note a significant rise, despite notable declines in recent years. The former Brazilian Environment Minister Marina Silva recently announced that the level of deforestation is unprecedented and that the rise in the price of commodities, such as soya, could have influenced the rate of forest clearing. ${ }^{63}$ This example highlights the volatile nature of commodity markets and how they may have an influence on

\footnotetext{
${ }^{58}$ See the submission of the International Centre for Research in Agroforestry (ICRAF) in Views, n. 32 above, at 25.

${ }^{59} \mathrm{~A}$ concern expressed many times by Tuvalu (personal observation) and noted conversely by Belize et al. as an opportunity. See Belize et al., n. 6 above, at 6 .

${ }^{60}$ As pointed out by Austria: see Austria on behalf of the European Community and its Member States, Views on Issues Relating to Reducing Emissions from Deforestation in Developing Countries, Focusing on Relevant Scientific, Technical and Methodological Issues, and the Exchange of Relevant Information and Experiences, including Policy Approaches and Positive Incentives: Recommendations on any further Process to Consider the Issues, in Issues, n. 10 above, at 7 .

${ }^{61}$ As noted by Indonesia, n. 14 above, at 7 . This is also noted by Panama et al. See Panama on behalf of Costa Rica, El Salvador, Guatemala, Honduras, Nicaragua and Panama, Reducing Emissions from Deforestation in Developing Countries: Approaches to Stimulate Action, in Issues, n. 10 above, at 107.

62 See Norway, n. 52 above, at 101

${ }^{63}$ Anon, 'Brazil Announces Record Rate of Amazon Deforestation', ABC News (24 January 2008), available at: <http://www.abc.net.au/ news/stories/2008/01/24/2146057.htm>.
}

carbon trading.

As has been seen with afforestation and reforestation project activities under the CDM, there are means to account for non-permanence. In fact, parties have suggested various options to account for non-permanence in a market associated with REDD. These include selfinsurance, ${ }^{64}$ renewal or temporary crediting, ${ }^{65}$ sustained management and conservation of forests, ${ }^{66}$ banking carbon credits as a risk buffer, ${ }^{67}$ reducing future financial incentives to take account of deforestation emissions above the agreed level, banking credits and debits from one period to another ${ }^{68}$ insurance buffers by withholding a proportion of REDD credits for sale ${ }^{69}$ and various modifications of the above.

While such approaches do allow for a market fix to non-permanence, the fact that actions to reduce emissions from deforestation and forest degradation have a high propensity for reversal suggests that a market-based approach carries significant risk factors. The market may be able to financially compensate for this risk, but the atmosphere cannot. Subsequently, those most vulnerable to the impacts of climate change will suffer.

\section{UNDERMINING THE MARKET}

Adding new REDD carbon credits to the carbon market, in potentially significant quantities, is inevitably going to influence the price of carbon. It is highly likely that the price will drop as supply exceeds demand. ${ }^{70}$ Some suggest that this is beneficial as it lowers the overall cost of

\footnotetext{
${ }^{64}$ Whereby land stewards produce more services than they have contracted (by planning extra areas for carbon offsets). This approach may be difficult in a national baseline context. See S.J. Scherr et al., n. 51 above, at 47.

${ }^{65}$ This is similar to the approach applied in the CDM. See S. Prior et al., 'A Carbon Stock Approach to Creating a Positive Incentive to Reduce Emissions from Deforestation and Forest Degradation', Joint Submission to the UNFCCC Secretariat on Reducing Emissions from Deforestation in Developing Countries (The Centre for International Sustainable Development Law and the Global Public Policy Institute, 23 February 2007), at 7.

${ }^{66}$ As suggested by Austria on behalf of the European Community, n. 60 above, at 8 .

${ }^{67}$ As suggested by Bolivia. See Government of Bolivia, Reducing Emissions from Deforestation in Developing Countries: Approaches to Stimulate Action, in Issues, n. 10 above, at 21.

${ }^{68}$ See Germany on behalf of the European Community, n. 48 above, at 55 .

${ }^{69}$ L. Peskett and Z. Harkin, 'Risk and Responsibility in Reduced Emissions from Deforestation and Degradation', Forest Policy and Environment Programme Forestry Briefing (1 December 2007), 1, at 7 .

${ }^{70}$ Some suggest that the price of carbon could fall by $40 \%$ in 2020 if REDD credits are added to the market. See N. Anger and J. Sathaye, 'Reducing Deforestation and Trading Emissions: Economic Implications for the post-Kyoto Carbon Market', Centre for European Economic Research Discussion Paper No. 08-016, at 15, available at: <ftp://ftp.zew.de/pub/zew-docs/dp/dp08016.pdf>.
} 
meeting the goals of the Convention. ${ }^{71}$ On the other hand, there is a serious and authoritative concern expressed by Stern $^{72}$ and others ${ }^{73}$ that there is a risk of destabilizing the crucial process of strengthening existing strong carbon markets if deforestation was integrated into the market. Establishing cheap carbon credits from reducing emissions from deforestation could undermine efforts to reduce emissions in other sectors, particularly renewable energy technologies, where higher carbon prices are needed to make these technologies economically viable. While it could produce benefits for addressing deforestation, it could significantly hinder global efforts to reduce greenhouse gas emissions across the board. This point is often forgotten. Furthermore, low carbon prices for deforestation may not meet the opportunity cost of other competing land uses and uses of forests, such as timber extraction or soya production, hence making efforts to reduce deforestation less economically possible. One commentator goes so far as to suggest that forestry is not ready 'to play in the carbon market'. ${ }^{74}$

There are approaches that could, in part, address the market effects of adding large, new sources of REDD carbon into the market. One option, as Stern suggests, is to ensure that there is a strong demand for emissions reductions. $^{75}$ This can be achieved by dramatically increasing Annex I targets for the next commitment period. $^{76,77}$ It remains to be seen whether this is a politically palatable option for Annex I parties. Some may see this as an opportunity to offset a large portion of the reductions targets in the next commitment period. Others may be concerned that they will have to carry an unfair share of the emissions reduction burden in the next commitment period. Ministers in Annex I countries that are keen to see a more global approach to addressing climate change, may not see this favourably.

Ironically, some of the developing countries that are keen to promote a new REDD carbon market do not want these new credits to weaken the existing flexibility mechanisms by lowering the market price of carbon. ${ }^{78}$

\footnotetext{
${ }^{71}$ This is noted by Gabon et al. See Gabon on behalf of Central African Republic, Cameroon, Congo, Equatorial Guinea, Democratic Republic of the Congo and Gabon, Peru, in Views, n. 32 above, at 38. ${ }^{72}$ See N. Stern, n. 10 above, at xxvi.

${ }^{73}$ See, for example, Republic of Korea, Views of KFS on the Issues Regarding Reducing Emissions from Deforestation in Developing Countries, in Issues, n. 10 above, at 115.

${ }^{74}$ As noted by Paul Ekins, in K. Alvarenga and W. McPherson, n. 21 above, at 4 .

${ }^{75}$ Ibid.

${ }^{76}$ As suggested by Mexico, n. 33 above, at 70 .

${ }^{77}$ See Belize et al., n. 6 above, at 4, which suggests that Annex I targets would need to be elevated by $9 \%$.

${ }^{78}$ See for example: Peru on behalf of Colombia, Costa Rica, Ecuador, Mexico, Nicaragua, Panama and Peru, Reducing Emissions from Deforestation in Developing Countries: Approaches to Stimulate Action, in Issues, n. 10 above, at 112.
}

It appears to be a case of 'having one's cake and eating it too' ${ }^{79}$

Another approach to minimize a weakening of the market is to quarantine the REDD market from other carbon markets. Under this approach, REDD carbon credits would not be fungible or tradeable in the general carbon market. In effect, REDD would have its own cap and trade market. This has been called the 'dual market approach' ${ }^{80}$ Proponents of the dual market suggest that it keeps separate an emerging market (REDD) from the more mature carbon market until questions of market volatility have been resolved. Another similar approach would be to apply quantitative restrictions to crediting from REDD. ${ }^{81}$

\section{LEAKAGE}

One of the potentially most significant pitfalls of REDD carbon markets is the concept of leakage, or emissions displacement. Simply put, leakage occurs when mitigation actions in one area may result, directly or indirectly, in emission increases in another area.$^{82}$ For example, stopping an area from being logged by establishing a protected area may lead to logging taking place in another location as the demand for logging has not changed. Leakage has the potential to totally undermine gains from reducing emissions from deforestation and forest degradation and, in fact, may lead to an increase in emissions. For example, if a carbon credit (or emission offset right) is generated through a REDD mechanism and leakage occurs, the atmosphere witnesses the emissions from the activity that was seeking the offset, plus the emission from the leaked deforestation. Subsequently the atmosphere is worse off. ${ }^{83}$ For those concerned about the impacts of climate change, this consequence is unacceptable.

Unfortunately, concerns about international leakage in particular appear to be significantly overlooked by many countries and even by the IPCC. Some forestry experts even infer that leakage should not be considered as the IPCC Good Practice Guidance does not

\footnotetext{
${ }^{79}$ To have one's cake and eat it is to want more than one can handle or deserve, or to try to have two incompatible things.

${ }^{80}$ See M. Ogonowski et al., Reducing Emissions from Deforestation and Degradation: 2007, The Dual Markets Approach (Center for Clean Air Policy, August 2007), at i, available at: <http://www.ccap.org/ international/FINAL\%20REDD\%20report.pdf>.

${ }^{81}$ As suggested by Norway, n. 52 above, at 101.

${ }^{82}$ As described by the USA, Views on Issues Related to Further Steps under the Convention Related to Reducing Emissions from Deforestation in Developing Countries: Approaches to Stimulate Action (UNFCC/SBSTA/2007/MISC.14, 10 September 2007), at 43.

${ }^{83}$ For a further explanation of this concept see Tuvalu, Views on the Range of Topics and Other Relevant Information Relating to Reducing Emissions from Deforestation in Developing Countries (FCCC/SBSTA/2007/MISC.2/Add.1, 3 April 2007), at 14.
} 
consider leakage for other sectors. ${ }^{84,85,86}$ This is a lamentable and foolhardy attitude as it suggests that global emissions, wherever they occur, are not the principle concern. If there is one issue that underscores the myopic view of the forestry sector in the context of REDD, it is its perspective on leakage. In essence, often the general view is that forestry outcomes are more important than outcomes in addressing climate change.

In consideration of the issue of international leakage, one only needs to look at the trade in timber products. It becomes very evident that a global market for tropical timber, either as round logs or sawn timber, is substantial and ever growing. The demand for wood products coming from China alone is enormous. In 2003, China imported around 42 million cubic metres of timber products and 52 million cubic metres of pulp and paper. ${ }^{87}$ Russia, Malaysia and Indonesia were the three largest suppliers, with New Zealand, Gabon, Germany, Papua New Guinea, Thailand and the USA, Canada and Myanmar making up the second tier of countries that supplied China. For pulp and paper, Indonesia, Russia, Canada, South Korea, the USA, Taiwan, Brazil and Chile were the major suppliers. ${ }^{88}$ Some of these suppliers are not necessarily the source country for this timber. As the authors of these statistics indicate, some of the wood is sourced from regions where low cost 'cut and run' logging is prevalent. ${ }^{89}$ The logical conclusion to this observation is that efforts to eliminate deforestation or forest degradation in some countries will force the 'cut and run' industry to move on to other locations - a classic example of international leakage. Considering that many of the timber companies operate in all tropical regions, moving on would not be a significant economic burden for them. Furthermore, the Chinese market has started to increase its investment in Africa, with major forest product trade relations established in Gabon, Cameroon, Equatorial Guinea, the Democratic Republic of Congo and Mozambique. Nearly all African timber exports to China are unprocessed

\footnotetext{
${ }^{84}$ See J.A. Sathaye and K. Andrasko, 'Editorial: Special Issue on Estimation of Baselines and Leakage in Carbon Mitigation Forestry Projects', 12 Mitigation and Adaptation Strategies for Global Change, (2007), 963-970, at 969.

${ }^{85}$ The IPCC suggests that leakage effects are no higher in forestry than in other sectors. This tends to reflect the attitude of others, which suggests that if leakage occurs in other sectors, why should it be a concern in the forestry sector? See G-J. Nabuurs et al., n. 5 above, at 571 .

${ }^{86}$ The United Nations Food and Agriculture Organization (FAO) considers that the effects of local leakage are a concern. This tends to suggest that this institution is not concerned about international leakage. See $\mathrm{FAO}$, in Views on the range of topics and other relevant information relating the REDD (FCCC/SBSTA/2007/MISC.3, 2 March 2007), at 18.

${ }^{87}$ Z. Chunquan, R. Taylor and F. Guoquiang, China's Wood Market, Trade and Environment (Science Press, 2004), at 20, available at: $<$ www.wwfchina.org/wwfpress/publication/forest/Chinawood.pdf>.

${ }^{88} \mathrm{lbid}$., at 22 and 23

89 Ibid., at 24
}

๑) 2008 The Author. Journal compilation ๑ 2008 Blackwell Publishing Ltd. $\operatorname{logs} .^{90}$ Needless to say, China is not the only country creating a demand for tropical forest products. In 2005, according to the ITTO, Japan and the USA remained the two largest markets for secondary processed wood products from ITTO supplier countries, although there is significant competition from China. ${ }^{91}$ Demand for tropical timber products is also significant in Europe ${ }^{92}$ and is on the rise. ${ }^{93}$ However, the statistics from the ITTO are based on incomplete data sets, suggesting that the full extent of the timber trade and, subsequently, potential leakage in the carbon market, will be difficult to assess..$^{94,95}$

The issue of leakage, particularly in relation to the timber trade, is compounded by the fact that significant quantities of tropical timber products entering the international market are considered to be illegal. The extent of illegal logging is difficult to assess as statistics on the trade do not appear in official trade registers. Rough estimates suggest that each year, US $\$ 23$ billion of forest products are produced globally from illegally harvested timber. Almost 25\% of hardwood lumber traded globally is of suspicious origin and almost 30\% of hardwood plywood traded globally is of suspicious origin. ${ }^{96}$

Various countries and commentators have suggested ways of addressing leakage in the context of REDD. With respect to international leakage (across international borders), some suggest that universal coverage of a REDD mechanism will address this issue. ${ }^{97,98}$ Considering that all developing countries may not wish to take on emission reduction targets, as suggested by the 'Annex C' group, or may not have the capacity to develop

\footnotetext{
${ }^{90}$ See K. Canby, 'China and the Global Market for Forest Products', Proceeding of the 1st Update Meeting on Illegal Logging and Associated Trade (8 March 2007), at 11, available at: <www.forest-trends.org/ .. ./meetings/washington_2007/lllegal\%20Logging\%203.8.07\%20-\%20 Participants\%20List.pdf>.

${ }^{91}$ International Tropical Timber Organization, Annual Review and Assessment of the World Timber Situation (Document GI-7/06, 2006).

${ }^{92}$ The EU imports around $45 \%$ of all timber exported from the Amazon Basin, while Cameroon and Gabon supply $80 \%$ of the region's timber exports to the EU. See J. Hewitt, Failing the Forests: Europe's Illegal Timber Trade (WWF-UK, 2006), at 2, available at: $<$ http://assets. panda.org/downloads/failingforests.pdf>.

${ }_{93}$ See K. Alvarenga and W. McPherson, n. 21 above, at 4.

${ }^{94}$ In 2006, the ITTO undertook a Joint Forest Sector Questionnaire. With respect to Data Quality Indicators, the ITTO received no responses from Central African Republic, China, Democratic Republic of Congo, Ecuador, Liberia, Nepal, Nigeria, Papua New Guinea, Republic of Korea and Vanuatu. See ITTO, n. 91 above, at 43.

${ }^{95}$ The ITTO also noted in its report that there were significant discrepancies between the trade flows reported by Malaysia and trading partners China, Hong Kong and Thailand in recent years: see ibid., at 45 .

${ }^{96}$ T. Curtin, 'What Constitutes Illegal Logging?', 22:1 Pacific Economic Bulletin (2007), 125.

${ }^{97}$ See Austria on behalf of the European Community, n. 60 above, at 8 .

${ }^{98}$ See ICRAF, n. 58 above, at 26.
} 
national baselines to assess and address deforestation rates within their own country, this suggestion is too simplistic. It is hard to envisage how an international carbon trade on REDD can operate while international leakage remains a concern. Others suggest that national baselines will resolve leakage, presumably under the belief that international leakage does not exist. ${ }^{99}$

Efforts are underway to attack the problem of the illegal trade in timber - a compounding factor of international leakage. Several years ago, the World Bank and G-8 initiated the Forest Law Enforcement and Governance (FLEG) process among producer and consumer nations to combat illegal logging in Asia and Africa. ${ }^{100}$ Linked to this are the EU Forest Law Enforcement, Governance and Trade (FLEGT) ${ }^{101}$ and voluntary partnership agreements (whereby only timber certified as legal will be allowed to enter the market), ${ }^{102}$ as well as the President's Initiative Against Illegal Logging ${ }^{103}$ and other initiatives by non-governmental organizations (NGOs) such as the Responsible Asia Forest and Trade programme. ${ }^{104}$

While recognizing initiatives to address illegal logging, it has not gone unnoticed that some of the countries that are the key proponents of a REDD market mechanism are some of the worst perpetrators of illegal logging. ${ }^{105}$ Papua New Guinea rates prominently in this context. Studies suggest that the majority of logging in

\footnotetext{
${ }^{99}$ M'A. Santilli et al., 'Tropical Deforestation and the Kyoto Protocol', 71 Climate Change (2005), 267-276, at 271.

100 See G-J. Nabuurs et al., n. 5 above, at 566.

${ }^{101}$ B. Gardiner, 'Linking Timber Trade and Forest Practice: How the UK uses Market Power to Tackle Illegal Logging', Proceeding of the 1st Update Meeting on Illegal Logging and Associated Trade (8 March 2007), n. 90.

${ }^{102}$ Environmental Investigation Agency (EIA)/Telepak, The Thousand-Headed Snake: Forest Crimes, Corruption and Injustice in Indonesia (Environmental Investigation Agency/Telepak, 2007), at 18 and 26, available at: <http://www.eia-international.org/files/ reports135-1.pdf>.

${ }^{103}$ The President's Initiative Against Illegal Logging, established in 2002, aims to assist developing countries to combat illegal logging, the sale (including for export) of illegally harvested timber products, and corruption in the forest sector. The Initiative focuses on three regions: the Congo Basin, Amazon Basin and Central America and South and South-East Asia. See S. Caswell, 'Overview of the President's Initiative Against Illegal Logging (PIAIL)', Proceeding of the 1st Update Meeting on Illegal Logging and Associated Trade, n. 90 above, at 1 .

${ }^{104}$ The Responsible Asia Forestry and Trade (RAFT) programme is an initiative of The Nature Conservancy and ECO-Asia with assistance from USAID. It aims to protect forests in Asia by transforming the market for tropical timber to achieve sustainability. See J. Hurd, 'Stemming the Flow of Illegal Wood: Experience from Indonesia and the Region', in n. 101 above, at 8.

${ }^{105}$ For example, undercover interviews by EIA representatives allege that Singapore timber merchants supply false documents for the trans-shipment of timber through Singapore. See A. von Bismarck, 'Recent Findings and Initiatives on Trade in Illegally Logged Timber by the EIA', in Proceeding of the 1st Update Meeting on Illegal Logging and Associated Trade, n. 90 above, at 9.
}

Papua New Guinea is considered 'unlawful'. ${ }^{106,107}$ Furthermore, current official log prices indicate that the industry has been unprofitable for a number of years - yet the logging continues and companies seek access to new areas. ${ }^{108}$ As Pearce suggests, 'if they can't police logging, why should they be able to police not logging?'. ${ }^{109}$ This could lead one to ponder whether a market-based REDD mechanism could become another form of rent seeking by unscrupulous industry and government officials. ${ }^{110}$

Another option to effectively eliminate consideration of international leakage is to introduce a definitional restriction on the term leakage in any REDD agreement. This trump card was played in negotiations on the issue of leakage in afforestation and reforestation projects under the CDM. The definitional 'fix' meant that only leakage that could be measured and attributed to the project activity would be considered. ${ }^{111}$ This may be useful for the REDD carbon market opportunists, but would do nothing for addressing climate change. Leakage would continue.

\section{(a) Demand-Side Management of Interna- tional Leakage Another more complex option to address international leakage would be to initiate demand-side measures so that importing countries would be required or encouraged to ensure that forest product imports are derived from sustainably managed forests and not as a result of deforestation or forest degradation.}

If demand-side management was included in the carbon market, it may be necessary to create disincentives for

\footnotetext{
${ }^{106}$ Anon, Logging, Legality and Livelihoods in PNG: Synthesis of Official Assessments of the Large-Scale Logging Industry (Forest Trends, 2006), at 2.

${ }^{107}$ Another report alleges that the logging industry in PNG is 'synonymous with political corruption, police racketeering and the brutal repression of workers, women and those who question its ways'. See Anon, Bulldozing Progress: Human Rights Abuses and Corruption in Papua New Guinea's Large Scale Logging Industry (The Centre for Environmental Law and Community Rights, The Australian Conservation Foundation, August 2006), at 38, available at: <http:// www.acfonline.org.au/uploads/res/res_acf-celcor_full.pdf\#search\% 22 Bulldozing $\% 20 \% 22>$.

${ }^{108}$ Ibid., at 3.

${ }^{109}$ F. Pearce, 'Consensus Hides Cracks in Deforestation Plan', Telegraph (19 December 2007), at 1, available at: <http://www. telegraph.co.uk/earth/main.jhtml;jsessionid=XQFOVDJ2QOYDRQFI QMFCFF4AVCBQYIV0?xml=/earth/2007/12/19/eafred119.xml>.

${ }^{110}$ Examples of rent-seeking in the carbon market have already begun to surface. See S.J. Scherr et al., n. 51 above, at 28.

${ }^{111}$ This states that 'leakage' is the 'increase in greenhouse gas emissions by sources which occurs outside the boundary of an afforestation or reforestation project activity under the CDM which is measurable and attributable to the afforestation or reforestation project activity'. See Decision 19/CP.9, Modalities and Procedures for Afforestation and Reforestation Project Activities under the Clean Development Mechanism in the First Commitment Period of the Kyoto Protocol (FCCC/CP/2003/6/Add.2, 30 March 2004), Annex.
} 
importing 'REDD unfriendly' forest products. Essentially if Annex I parties wish to seek carbon credits from the REDD market, they should also be ready to accept carbon deficits as well. Therefore, it may be possible to create what could be called 'carbon deficit levies' (CDLs) for importing countries. Annex I parties would be subject to CDLs if they import carbon stocks resulting from deforestation or forest degradation activities in developing countries. For this to operate, Annex I parties would need to register all imported carbon stocks for tropical forested countries in their national transaction logs. These would appear as an emission. An assessment would need to be made on the place of origin of these carbon stocks and then a greenhouse gas emission factor would be allocated to these stocks and would be registered in the national transaction log as a deficit. The resultant CDL would be based on an estimate of overall emissions created by the logging operation from where the carbon stocks were derived. This may appear to be an unduly complicated system, but it could be made simpler as methodologies for estimating emissions factors in direct rainforest regions develop over time. Already there are methodologies for estimating greenhouse gas emissions resulting from logging operations based on an assessment of damage to the rainforest canopy. ${ }^{112}$ Estimates for soil carbon loss would also need to be made. If an Annex I party could not identify the origin of imported carbon stocks it would be subject to the highest CDL.

The IPCC could be tasked with developing a metric for the estimation of emissions depending on the source of the imported timber products. Once this calculation is made, a CDL could be applied to an Annex I assigned amount. In effect, it would be the opposite of acquiring Certified Emission Reduction (CERs) under the CDM. They would be acquiring emission increases to add to their assigned amount.

The idea of a CDL was first proposed by the author at the Third Informal Dialogue on LULUCF in Reykjavik, Iceland, from 7-9 May 2008. ${ }^{113}$ Reception to this idea was generally not favourable, particularly by the Annex I country representatives, as they thought that attribution of sustainably and unsustainably managed tropical timber products would be difficult to achieve. Their reticence may also be related to the fact that they did not want to be responsible for emissions in other countries, even though their markets were driving this deforestation.

\footnotetext{
${ }^{112}$ For example, Asner et al. have calculated an 'area integrated gap fraction' (AIGF) to measure damage to the canopy in Brazilian Amazon rainforests as a result of logging. They calculate a damage to canopy in the range of $10-40 \%$ resulting from logging. See G.P. Asner et al., 'Condition and Fate of Logged Forests in the Brazilian Amazon', 103:34 Proceedings of the National Academy of Science (2006), at 12947.

${ }^{113}$ The Chairman's summary of this meeting has yet to be published.
}

A future trading regime developed under the Convention, which may include the USA participating in fungible trade arrangements with other Kyoto Annex I parties, should include a CDL factor if REDD is included in the carbon market. Non-Annex I parties that are major importers of tropical timber could also be subject to a CDL factor. Perhaps a reduction in the eligibility to sell CER credits under the CDM, or a discount value for CERs, could be applied. While initiating demandside measures, such as the CDL, would be difficult, it is really the only way to properly close the loop on international leakage and work towards reducing emissions from deforestation and forest degradation.

Such measures may appear to be unnecessarily punitive for tropical timber importing countries, but if Annex I countries are to receive carbon offsets from a REDD market, they should also receive carbon deficits as well. For the non-Annex I countries that expect to receive financial support for protecting their own forests (see discussion below on conservation), they should bear some responsibility for importing products derived from deforestation and forest degradation activities in other countries.

(b) Sub-National Leakage For leakage within sub-national REDD projects, there are other means to consider leakage. The first is to establish a national baseline and monitoring system to theoretically pick up leakage within national boundaries. ${ }^{114}$ This would mean that sub-national projects would require both project level baselines and overall national baselines. This would undoubtedly add to the transaction costs of sub-national projects, but it would give some level of guarantee of picking up national leakage. Other means of factoring in leakage include what some have called 'methodological design', to include emission reference levels for each area of activity. ${ }^{115}$ A more elaborate means of accounting for project leakage includes the use of a 'non-linear dynamic optimization model' to quantify how a project might cause the loss of carbon outside the project boundary. ${ }^{116}$ Another approach is to avoid projects where leakage may be a concern. ${ }^{117}$ Discounting carbon credits to 'account' for leakage is another option. ${ }^{118}$

Some of the approaches for assessing leakage may work for local causes but none of them will resolve international leakage. In this context, some countries

\footnotetext{
${ }^{114}$ This is an approach suggested by the IPCC. See G-J. Nabuurs et al., n. 5 above, at 567.

115 See Colombia, n. 36 above, at 23.

${ }^{116}$ See Governments of Bolivia et al., n. 10 above, at 17.

117 Paraguay, Honduras, Mexico, Panama, Paraguay and Peru, Views on Issues Related to Further Steps under the Convention Related to Reducing Emissions from Deforestation in Developing Countries: Approaches to Stimulate Action (UNFCC/SBSTA/2007/ MISC.14, 10 September 2007), at 44.

118 Ibid.
} 
who prefer a national market REDD mechanism believe that the methodological impediments that prohibited REDD being considered in the CDM in the first commitment period remain. ${ }^{119}$ In essence they are saying that sub-national REDD projects will not work because of leakage problems. This is an intriguing admission, as some of these countries continue to support sub-national REDD activities in the submissions.

\section{INTERNATIONAL TRADE IMPLICATIONS OF REDD ACTIONS}

Introducing a new international carbon market for REDD may generate new complications for international trade. Efforts to address illegal logging as a means to reduce leakage in the REDD market may trigger concerns about protectionism. It is highly likely that countries that may be introducing trade restrictions associated with illegal imports may not be doing this for entirely altruistic reasons. They may, in part, be doing so to protect their own forestry industry. ${ }^{120}$ Efforts to introduce sustainable forest management (SFM) requirements in the timber trade may also be perceived by some to be non-tariff barriers. ${ }^{121}$

\section{ADDITIONALITY}

If the REDD mechanism is to include carbon offsets against Annex I commitments, then additionality should be a consideration. The idea behind the need to address 'additionality' is to avoid giving credits to projects that would have happened anyway. Essentially, it is a test that the carbon trading mechanism is having an effect and hence leads to measures that ensure that the activity reduces emissions more than would have occurred in the absence of the activity. The REDD mechanism should be derived directly as a result of the carbon market activity, rather than through other financial means. The offset should be a direct replacement. Otherwise countries are subsidising the carbon market. Determining additionality for a REDD mechanism for national baselines could be difficult as it would be difficult to differentiate between actions that have occurred as a result of the carbon finance compared with other initiatives not related to carbon finance. If, however, the REDD mechanism is based on

\footnotetext{
${ }^{119}$ See Belize et al., n. 6 above, at 7.

${ }^{120}$ This conclusion could be drawn from the fact that the American Forest Product Association suggests that if 'illegal' timber imports were blocked, the price of roundwood would increase by $19 \%$, lumber by $7 \%$ and wood panel by $6 \%$, and that eliminating 'suspicious' timber from world trade would enable the USA to increase its own sawnwood, wood panel and roundwood exports by over US $\$ 460$ million per annum. See T. Curtin, 'The Great "Illegal" Logging Swindle' (a summary of the author's paper, 'What Constitutes Illegal Logging?', 22:1 Pacific Economic Bulletin (March 2007), 125), available at: <http://www.timcurtin.com>

${ }^{121}$ See Indonesia, n. 14 above, at 11.

๑) 2008 The Author. Journal compilation ๔ 2008 Blackwell Publishing Ltd.
}

an Annex C commitment, as suggested by the Annex C group, then additionality is not an issue as all actions taken would be considered to be additional, as the carbon finance only comes into play when a country exceeds its emissions reduction target. As in CDM projects, additionality would need to be considered for subnational REDD project activities.

\section{SOVEREIGNTY AND RIGHTS TO LAND}

There is a concern that if a REDD mechanism is based on the international trade in carbon it could have implications for the sovereignty of a country. The sovereignty concern appears to relate to the fact that the international carbon market may dictate how a government would manage its forests. ${ }^{122}$ This concern was noted by a number of African and Latin American countries. ${ }^{123,124}$ Brazil has also been a strong advocate for the protection of national sovereignty and as a consequence this appears to be one of the major reasons why it opposes a market-based approach. ${ }^{125}$

Another concern being expressed regarding an international REDD carbon market is the effects that such a regime may have on the rights of indigenous peoples and local communities. In some situations, the property rights of indigenous peoples and local communities are far from settled, much less the right to benefit from the carbon market. Introducing carbon rights over land occupied and used by these people may have the potential to further compromise their tenure and use of the land. ${ }^{126}$ There is a real fear among some indigenous peoples and some NGOs that the establishment of protected areas as a response to REDD could seriously compromise their rights to land. Based on past experience, statements like identifying and promoting alternative sustainable livelihoods near protected areas', ${ }^{127}$ while presumably well intentioned, is cold comfort for some indigenous peoples. ${ }^{128}$

It is for this reason that a number of indigenous peoples' organizations expressed concern about the launching of the World Bank's Forest Carbon Partnership Facility in Bali. These groups stressed that they had

\footnotetext{
${ }^{122}$ See K. Alvarenga and W. McPherson, n. 21 above, at 6.

${ }^{123}$ See Democratic Republic of Congo et al., n. 11 above, at 27.

124 See Peru et al., n. 78 above, at 111.

${ }^{125}$ Concern about sovereignty is not explicitly stated by Brazil, but can be inferred from statements from government officials and others (personal observation). See also comments about sovereignty in K. Alvarenga and W. McPherson, n. 21 above, at 4.

126 This concern is acknowledged by S.J. Scherr et al., n. 51 above, at 27.

127 This is one of a number of approaches suggested by the US Government with respect to REDD actions. See USA, Reducing Emissions from Deforestation in Developing Countries: Approaches to Stimulate Action, in Issues, n. 10 above, at 118.

${ }^{128}$ Personal conversation with indigenous peoples' groups.
} 
not been consulted about the establishment of this facility, even though it may have implications for their rights to use their lands. ${ }^{129}$

If a REDD market mechanism was developed, it would need to clearly spell out how carbon rights are defined, how these rights would affect land ownership or use, and whether there were adequate legal provisions to protect the rights of indigenous peoples and local communities. ${ }^{130,131}$

In conclusion, market-based REDD mechanisms may bring new money into actions to address deforestation and forest degradation, but there are inherent risks. These risks may be greater than the benefits.

\section{NON-MARKET FUNDING OPPORTUNITIES}

Some countries, notably Brazil and Tuvalu, have suggested that a new REDD mechanism could be based on non-market approaches. Brazil in particular has emphatically stated that it does not envisage that a REDD mechanism could be used by Annex I countries to meet their quantified greenhouse gas emission limitation and reduction commitments under the Kyoto Protocol. ${ }^{132}$ Brazil further suggests that any REDD arrangement would be voluntary and cannot generate future obligations, goals, targets or timeframes. ${ }^{133}$ Therefore, it does not support the proposal by the Annex C group, preferring instead a REDD mechanism based on non-market finances.

The non-market REDD group, like the market REDD groups, have differences of opinion over whether the REDD mechanism should be national or sub-national. Brazil has proposed the distribution of financial incentives to national governments that demonstrates, using national reference scenarios, in a transparent and credible manner, a reduction in their emissions from deforestation. ${ }^{134}$ Demonstration of emission reductions would be based on ex-post results. Tuvalu, on the other hand, has suggested a more local approach whereby Community Forest Retention Trust Accounts are established to pay for REDD activities. These trust

\footnotetext{
129 See, for example, A SEED Europe and other NGOs, NGO Statement on the World Bank's Proposed Forest Carbon Partnership Facility (FCPF) (30 November 2007), at 3, available at: $<$ http://www.forestpeoples.org/documents/forest_issues/ unfccc bali ngo statement nov07 eng.shtml>.

${ }^{130}$ For a commentary on such issues, see L. Peskett and Z. Harkin, n. 69 above, at 4

${ }^{131}$ Also see n. 127 above, at 1.

132 See Brazil, Views on the Range of Topics and Other Relevant Information Relating to Reducing Emissions from Deforestation in Developing Countries, in Views, n. 32 above, at 21.

133 Ibid., at 22.

134 Ibid.

๑ 2008 The Author. Journal compilation @ 2008 Blackwell Publishing Ltd
}

accounts would draw from an International Forest Retention Fund (IFRF), but the money would not be directed through national governments, although some degree of national oversight would be necessary. ${ }^{135}$

There have been a number of suggestions for new funds for REDD. Apart from the IFRF, Mexico and others have suggested the establishment of an 'Avoided Deforestation Carbon Fund'. ${ }^{136,137}$ To source money for this fund, Mexico suggests that a levy be placed on Emission Reduction Units (ERUs) generated by activities under Article 6 of the Kyoto Protocol (Joint Implementation) and on AAUs generated under Article 17 of the Protocol (Emissions Trading). It suggests that the method would be similar to that applied to the levy on CERs from Article 12 of the Protocol (CDM). ${ }^{138}$ The Democratic Republic of Congo and others suggest the establishment of a stabilization fund for 'remunerating forest carbon stocks'. They suggest that money for this fund could come from taxes on the sale of REDD credits, additional funding provided by Annex 2 countries, taxes on carbon-intensive goods and services and other financial instruments. ${ }^{139}$ Another suggestion is to apply a tax on oil consumption in the EU and the USA, ${ }^{140}$ while others suggest: a levy on international transport; revenues from auctioning of credits in emissions trading schemes; and/or 'where emission trading schemes have a price cap, revenues generated from selling credits at the price-cap level'. ${ }^{141}$ Yet another country proposes a levy on the sale of military goods and related services. ${ }^{142}$ Some countries suggest that financing for REDD should be supplemental to existing development assistance. ${ }^{143}$

\section{ALLOCATING THE FUNDS}

A key process in setting up a new fund(s) for REDD will be to determine how the funds are allocated. This will be fundamental to ensure that the money goes to support REDD activities and not into the pockets of unscrupulous officials, or to be spent on actions that are not directly related to REDD. Furthermore, there would need to be an arrangement to ensure that funds would be directed to the communities on the ground. Tuvalu's proposal for local trust funds may go some way to ensuring local participation. ${ }^{144}$ Gabon and others

\footnotetext{
135 See Tuvalu, n. 83 above, at 15 .

136 See Mexico, n. 33 above, at 73

137 See Chile, n. 35 above, at 26.

138 Ibid.

139 See Democratic Republic of the Congo et al., n. 11 above, at 27.

140 See Belize et al., n. 6 above, at 5 .

141 See Paraguay et al., n. 117 above, at 44.

142 See Republic of Costa Rica, n. 44 above, at 66.

${ }^{143}$ Gabon on behalf of Cameroon, Central African Republic, Chad, Congo, Democratic Republic of the Congo, Equatorial Guinea and Gabon, Reducing Emissions from Deforestation in Developing Countries: Approaches to Stimulate Action, in Issues, n. 10 above, at 75.

${ }^{144}$ See Tuvalu, n. 83 above, at 15.
} 
also suggest a set process for determining the distribution of funds based on a weighting system according to criteria such as: total forest area, deforestation rate, forest area managed sustainably with approved management plan, certified forest area and protected areas. ${ }^{145}$ It is unclear how these criteria would be applied and how they could be used to rate one country over another.

\section{EXISTING REDD FUNDING OPPORTUNITIES}

While the new funding proposals have been placed on the negotiating table, the USA is keen to indicate that it already funds various REDD initiatives. These include funding initiatives through USAID such as the debt-for-nature swap programme in collaboration with a number of NGOs. ${ }^{146} \mathrm{El}$ Salvador suggests that existing funding arrangements under the UNFCCC and the Kyoto Protocol, such as the Special Climate Change Fund and the Adaptation Fund, should identify synergies with REDD activities and give priority to these programmes. ${ }^{147}$

The plethora of funding opportunities suggests that a REDD mechanism could survive without a direct link to the carbon market. Possibly the most interesting of these suggestions relate to the auctioning of AAUs from emissions trading and/or a levy on emissions from international aviation and maritime transport. These revenue sources have the potential to generate large sums of money (possibly within the realm of the funds requirements suggested by Stern). The challenges of sorting out the mechanics of establishing this funding mechanism may be a little complicated but not insurmountable. Individual Annex I countries, which are parties to the Kyoto Protocol, would need to pledge a certain percentage of the revenue gained from the auctioning of AAUs within their countries and/or a percentage of the revenue from levies applied to international aviation and maritime transport. Some international pledging arrangement would need to be established, otherwise some countries may not subscribe to an international REDD fund, preferring instead to sponsor bilateral activities. The idea of placing a levy on the sale of AAUs and ERUs also has promise, as this approach is already being applied with respect to a share of the proceeds from the sale of CERs under the CDM.

A significant downside to an arrangement that is linked to the Kyoto Protocol is that the USA, not being a party to the Protocol, would not be a revenue source.
As a consequence, a potentially sizeable source of funding would be absent. Nevertheless, it would be possible to develop fungible arrangements with any emission trading scheme developed in the USA so as to allow the USA to participate in such an arrangement. The USA should also be encouraged to participate in a levy scheme associated with international aviation and maritime transport.

\section{PITFALLS OF A NON-MARKET REDD MECHANISM}

The biggest uncertainty with a non-market REDD mechanism is whether the funding arrangements that are developed would provide sufficient funds to properly address REDD. This is a significant unknown but would need to be resolved in time for COP 15 in Copenhagen in 2009.

Overall, the potential for new money generated from levies, a share of proceeds of all the Kyoto mechanisms and the auctioning of tradeable units both within and outside the Kyoto Protocol is quite promising.

Many of the complications associated with market-based REDD mechanisms also apply to non-markets. The issues of measurement, permanence, leakage and rent seeking are still relevant. The significant difference is that if the approaches fail, they are not directly related to an emission offset, therefore the climate change implications are less.

\section{TRADE-RELATED IMPLICATIONS}

Despite the fact that non-market REDD mechanisms are not linked to the carbon market, there may be other trade implications. Argentina, for instance, notes that if a REDD mechanism is to be considered within the context of a 'payment for environmental services, ${ }^{148}$ it would be subject to GATS (General Agreement on Trade in Services) provisions. ${ }^{149}$ Others suggest that if positive incentives are introduced for REDD, these should be considered as non-actionable subsidies as long as they meet the criteria for 'Green Box' subsidies under Annex 2 of the World Trade Organization (WTO)'s Agreement on Agriculture, and hence should be allowed without restriction. ${ }^{150}$ These trade implications would need to be considered carefully.

\footnotetext{
145 See Gabon et al., n. 143 above, at 41.

146 See USA, n. 127 above, at 120.

${ }^{147}$ El Salvador, Reducing Emissions from Deforestation in Developing Countries: Approaches to Stimulate Action, in Issues, n. 10 above, 11 April 2005, at 69.

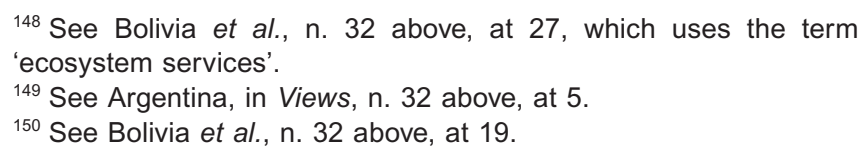




\section{CONSERVATION, THE SUSTAINABLE MANAGEMENT OF FORESTS AND ENHANCEMENT OF CARBON STOCKS IN DEVELOPING COUNTRIES}

Within the Bali Action Plan there are three actions that have been subtly separated from the positive incentives. These are 'the role of conservation, the sustainable management of forests and the enhancement of carbon stocks in developing countries'. As noted above, these terms are separated from REDD by a semi-colon and the words 'role of'. This distinction is quite significant as it implies that these three actions would not be eligible for the same 'positive incentives', i.e. market-based mechanisms, if such a REDD market was established. This distinction was intensely debated in Bali with some wanting these concepts included in the market and others not. ${ }^{151}$ Looking more specifically at these actions, the reasons for the distinction become more apparent.

\section{CONSERVATION}

India has been the key proponent of using the term 'conservation' based on the view that it has reduced its deforestation rate to near zero and needs money to conserve its remaining forests. ${ }^{152}$ In effect, India is saying that it wants a slice of the new REDD money pie, under the terminology 'Compensated Conservation'. ${ }^{153}$ While on the surface this appears reasonable, the fact that India has reduced its deforestation rate has nothing to do with climate change. Furthermore, as a consequence of reducing deforestation within its own country, its deforestation footprint is now extending out to many other tropical forest countries, as India is now a major importer of tropical timber products. It would be inappropriate to give carbon credits to a country that is protecting its own forests, while at the same time driving deforestation elsewhere due its demand for rainforest timber. It would also seem illogical to include conservation in the carbon market, as there is no real change in carbon stocks and hence nothing to trade. ${ }^{154}$

Nevertheless, it may be appropriate to use a proportion of a REDD fund to support the conservation of forests so long as there were commensurate provisions for penalising countries for importing products derived

\footnotetext{
151 Personal observation.

152 Personal observations made by the author of the Indian delegation at various REDD meetings.

153 India, in Views, n. 32 above, at 60.

${ }^{154}$ A point often made by Brazil. See Brazil, n. 132 above, at 21.

from deforestation and forest degradation activities. REDD conservation could be funded in the context of adaptation to the impacts of climate change. ${ }^{155}$ This would make sense as the protection of forests has many adaptation benefits, including the protection of watersheds and the prevention of erosion and landslides as a result of severe weather events.

\section{THE SUSTAINABLE MANAGEMENT OF FORESTS}

The concept of sustainable management of forests (SMF) was promoted by the Japanese delegation in Bali. The Japanese are keen proponents of SMF within their own country (although they are major importers of tropical timber derived from non-SMF practices). ${ }^{156}$ Most countries accepted that that SMF would, in fact, be a process that would contribute to reducing emissions from deforestation and forest degradation ${ }^{157,158}$ and hence there was little debate over including this concept.

The concept of SMF means many things to different people, but ostensibly it refers to the management of forests in such a way that ensures ongoing productivity of the forest. If applied in the context of REDD, it would mean the practice of ensuring that any logging operation was carried out in such a manner to allow the forest to recover from the logging activity. Smallscale selective logging, using low-impact equipment such as portable mills, is one type of SMF. It is unlikely that there will be a separate set of actions to address this concept as it would be part of most REDD activities. As noted above, however, requirements for SMF may have implications in the context of the WTO.

\section{THE ENHANCEMENT OF CARBON STOCKS}

The 'enhancement of carbon stocks' (ECS) is a concept that appears to have been raised by the Chinese in Bali. ${ }^{159}$ The Chinese also appeared to want a slice of the REDD pie, but as there is a net increase in carbon stocks in China (although there is still significant deforestation of primary forests in some parts of the country), they were keen to have an ECS included. Essentially the 'deal' between India and China meant that they could both get a slice of the REDD pie by

\footnotetext{
${ }^{155}$ As noted by Rodel Lasco, in R. Dimitrov and M. Gutiérrez, 'Summary of Forest Day', 148:1 Forest Day Bulletin (10 December 2007).

${ }^{156}$ See Japan, n. 53 above, at 91. There appears to be little difference between SMF and SFM (sustainable forest management) except that SMF is a collective term for multiple forests.

${ }^{157}$ As indicated in the US submission, n. 127 above, at 118.

${ }^{158}$ Also noted by Thailand, n. 54 above, at 80 .

159 Personal observation.
} 
adding concepts that suit their national circumstances. For China, ECS meant that it could continue to grow new plantations of introduced species while at the same time continue to deforest natural forests in other parts of the country. This would mean that there was a net increase in carbon stocks. For other countries, ECS represents a very broad range of possibilities. It could refer to soil carbon improvements through improved agricultural activities; it could refer to replanting of degraded forests; or it could refer to afforestation and reforestation activities (which are currently covered under the CDM). In essence, ECS could contribute to REDD by addressing some of the drivers of deforestation and forest degradation on land adjoining tropical forests as a means to increase agricultural productivity and decrease the need to clear rainforests. However, it would need to be considered carefully to ensure that countries do not apply a 'net' approach to deforestation by using the term.

Like conservation, ECS, if considered to be separate to REDD actions in general, may be best placed in the adaptation arena ${ }^{160}$ and could be eligible for funding under the Special Climate Change Fund and other sources. ${ }^{161}$

\section{THE BASKET APPROACH}

A number of countries have advocated for a 'basket approach $^{162}$ or 'flexible' approach ${ }^{163}$ (which are more or less the same thing). Advocates of the basket approach essentially suggest that all REDD options should be available under a REDD mechanism. This means that countries that are capable of developing national baselines and are willing to enter into a carbon market should be free to do so. Meanwhile, for those countries that would prefer to undertake sub-national carbon offset projects, they should be given the opportunity to do so. Those countries that are not capable or willing to enter the carbon market should be able to access funds from non-market sources. Furthermore, for those countries that have low rates of deforestation, they should be able to avail themselves of funding to assist them in protecting their carbon stocks.

On the surface, a basket approach appears to be a logical way forward. As noted by Bolivia and others, nations have varying development profiles, social structures, economic drivers, legal and regulatory frameworks

\footnotetext{
${ }^{160}$ See Panama et al., n. 61 above, at 104, which make the link between REDD actions and adaptation.

${ }^{161}$ As suggested by El Salvador, n. 147 above, at 69 .

${ }^{162}$ See for instance Belize et al., n. 6 above, at 9.

${ }^{163}$ Some countries, looking forward to carbon offset credits in the next commitment period, appear to be advocating for a 'flexible approach' to facilitate easy access to carbon credits to meet their commitments in the next period. See, for example, Australia, in Views, n. 32 above, at 8. See also New Zealand, in ibid., at 76.
}

and capacities for enforcement, monitoring and verification. ${ }^{164}$ A variety of actions should be available to meet the different capabilities of different countries. But the market may not be so charitable. It will pick the most capable and leave the rest to the ravages of other economic pressures such as the timber market. Consequently, international leakage will continue until all countries are brought into a consistently applied REDD mechanism. ${ }^{165}$ This will take considerable time. Therefore, a market-based basket approach is not ideal as it encourages leakage. However, the basket approach also has its problems as the basket weavers are likely to make a basket with a faulty carbon market, which may not properly mitigate climate change. This is the major flaw in any market-based approach. Not everyone will be able to participate in the market on a level playing field - a concept common to all markets.

Under a developed market-based approach, what we may see is the carbon market beginning to interact with the timber market and other economic drivers of deforestation such as agricultural expansion. One possible consequence, for example, is that the timber market will continue to $\log$ the easily accessible rainforests (at an unsustainable rate), leaving the degraded land available for agriculturalists. Consequently deforestation and forest degradation will continue in biologically important areas. Meanwhile, actors in the carbon market will buy the inaccessible forests where deforestation or degradation may have never been on the horizon. Meanwhile emission rights will have been traded away, allowing other countries to increase their emissions. Another possible consequence, as suggested by Malaysia, is that deforestation will accelerate in the near future so that countries can have a more favourable baseline from which to calculate emissions reduction credits thereafter. ${ }^{166}$

Alternatively, the basket approach could work if the carbon market was not part of the equation. The new REDD fund(s) would allocate financial support to fund various REDD activities, including national REDD actions, project-based activities and the other three actions defined in the Bali Action Plan, namely the role of conservation, sustainable management of forests and the enhancement of forest carbon stocks in developing countries. Furthermore, various enabling activities such as capacity building in developing national forest inventories, technology transfer, legislation development, illegal trade policing, etc., would also be included in the basket.

\footnotetext{
${ }^{164}$ See Bolivia et al., ibid., at 30.

${ }^{165}$ As noted by Germany on behalf of the European Community, n. 48 above, at 55 .

${ }^{166}$ Malaysia, Reducing Emissions from Deforestation in Developing Countries: Approaches to Stimulate Action, in Issues, n. 10 above, at 95 .
} 


\section{PRINCIPLES FOR A REDD MECHANISM}

Whether a new REDD mechanism is based on a market or on a non-market funding source, there are a number of principles that should apply to such actions to ensure that there are real and lasting outcomes. Some of the concepts suggested by parties and commentators, which could be incorporated into a set of principles, include that it: ensures a real impact in addressing climate change; ${ }^{167}$ is robust (accurate monitoring and reporting and including spatially explicit mapping with no gaps or overlaps); ${ }^{168}$ is complete (over time, space and forest type); ${ }^{169}$ ensures transparency (uniform monitoring and verification) $;{ }^{170,171}$ is sustainable, ${ }^{172}$ is pro-poor $;{ }^{173}$ promotes sustainable livelihoods; ${ }^{174}$ strengthens civil society; increases public awareness and participation; ${ }^{175}$ does not diminish the legal or customary rights of indigenous peoples or local communities; $;{ }^{176}$ strengthens legal institutions; ${ }^{177}$ supports sustainable forest management; ${ }^{178}$ is not funded through existing official development assistance (ODA) ${ }^{179}$ and promotes synergies with international initiatives and processes. ${ }^{180}$

Some countries have suggested other criteria, but they tend to conflict with the list above and hence may not be appropriate. ${ }^{181}$

\section{PUTTING THE REDD JIGSAW TOGETHER}

Establishing an effective regime on REDD under the UNFCCC, and possibly the Kyoto Protocol, will not be easy. It will require a step-by-step approach to build the capacities of rainforest countries. The first step will be to establish funding arrangements to allow all

\footnotetext{
${ }^{167}$ See Democratic Republic of Congo et al., n. 11 above, at 27.

${ }^{168}$ Suggested by Australia, n. 163 above, at 9 .

169 lbid.

$170 \mathrm{lbid}$.

171 See also Belize et al., n. 6 above, at 7 .

${ }^{172}$ See Japan, n. 53 above, at 62.

${ }^{173}$ See ICRAF, n. 58 above, at 28.

${ }^{174}$ See USA, n. 127 above, at 118.

175 Ibid.

176 See A SEED Europe et al., n. 129 above, at 3.

177 See L. Pesket and Z. Harkin, n. 69 above, at 4

${ }^{178}$ See Austria on behalf of European Community, n. 60 above, at 7.

${ }^{179}$ See Gabon et al., n. 143 above, at 77.

${ }^{180} \mathrm{Ibid}$.

${ }^{181}$ For instance, the EU refers to simplicity as an important criterion. While this may be ideal, it may not be consistent with the principle of being robust and may not lead to real outcomes to address climate change. See Portugal on behalf of the European Community, n. 45 above, at 47 .
}

๑ 2008 The Author. Journal compilation @ 2008 Blackwell Publishing Ltd. rainforest countries to develop national forest inventories. Further funding will be required so that institutional and legal arrangements can be developed to ensure the proper governance structures are in place to guarantee good governance and the protection of the rights of indigenous and local communities. As Malaysia suggests, a conservative and cautious approach will need to be adopted to ensure a clear and fair approach. ${ }^{182}$ National strategies to address illegal logging and other drivers of deforestation and forest degradation will also need to be developed and implemented. International cooperative action should be initiated to help accelerate the process of addressing the causes of deforestation and forest degradation through actions at the demand-side.

It may be possible to envisage at some time in the future, when these institutional arrangements are in place and all rainforested countries have adequate forest inventories, that a carbon market may be initiated. But a carbon market should not be initiated until then. A carbon market established immediately after 2009 will inevitably fail. It may survive financially (although this is not certain), but it will undoubtedly fail to effectively address climate change. Poor governance structures, inadequate inventory means and inevitable leakage will make the carbon market a flawed system.

At some stage during the next commitment period under the Kyoto Protocol, it may be possible to establish an assessment process to determine how far rainforest countries have moved towards establishing mechanisms to assess and arrest deforestation and forest degradation. Furthermore, there would need to be an assessment to determine whether demand-side measures have been put in place to guarantee that tropical forest products are derived from sustainable sources. Once the international community is satisfied that a global approach has been achieved, it may be possible to initiate an effective carbon market. Until then, it will be necessary to draw on innovative non-market funding arrangements to support REDD.

Ian Fry is the International Environmental Officer for the Environment Department of the Government of Tuvalu, and attends climate change meetings as part of the Tuvalu delegation. He is a Research Associate at the Climate Law and Policy Centre at the College of Law, the Australian National University, Canberra and is currently undertaking a part-time PhD at the Fenner School of Environment and Society at the Australian National University.

\footnotetext{
${ }^{182}$ See Malaysia, n. 166 above, at 94.
} 